\title{
Conhecimento e significado cultural da menopausa para um grupo de mulheres*
}

\author{
MENOPAUSE KNOWLEDGE AND EXPERIENCE FOR A GROUP OF WOMEN
}

CONOCIMIENTO Y SIGNIFICADO CULTURAL DE LA MENOPAUSIA PARA UN GRUPO DE MUJERES

\author{
Gabriela Maria C Costa', Dulce Maria Rosa Gualda²
}

\begin{abstract}
RESUMO
Este estudo etnográfico, realizado junto a um grupo de mulheres, teve como objetivo verificar o nível de conhecimento sobre a menopausa e compreender como ocorre a vivência deste estágio biológico próprio do sexo feminino. Para a coleta dos dados, usou-se a observação participante, a entrevista, mediante uso de gravador, além de desenhos previamente reproduzidos. A análise foi efetuada com base nos pressupostos teóricos, de método etnográfico e de alguns pressupostos do interpretativismo biográfico. Das narrativas coletadas, extraíram-se as categorias e os temas culturais. Assim, foi possível verificar que o processo da menopausa era entendido como resultante de uma construção singular, estando integrado a uma rede de significados, instituídos pelo grupo, os quais condicionam o conhecimento e a vivência dentro de determinados padrões culturais, entre eles, o fato de que a menopausa significa deixar de ser mulher.
\end{abstract}

\section{DESCRITORES}

Menopausa.

Saúde da mulher.

Antropologia cultural.

\begin{abstract}
This ethnographic study is aimed at understanding a group of women's knowledge about menopause and how they experience it. The methods used for data collection were participant observation, recorded interviews and previously produced drawings. Data were analyzed based on a theoretical framework using both the ethnographic method and biographic interpretativism. From the narratives the authors obtained the cultural categories and themes. Thus it was possible to conclude that menopause is understood as a result of a unique construction integrated to a network of meanings built by the group that condition knowledge and experience within certain cultural patterns, among them the fact that menopause means leaving womanhood behind.
\end{abstract}

KEY WORDS

Menopause.

Women's health.

Cultural anthropology.

\section{RESUMEN}

Este estudio etnográfico, realizado con un grupo de mujeres, tuvo como objetivo verificar el nivel de conocimiento sobre la menopausia y comprender cómo ocurre la vivencia de este período biológico propio del sexo femenino. Para la recolección de los datos, se usó la observación participante, la entrevista, mediante el uso de una grabadora, además de dibujos previamente reproducidos. El análisis se llevó a cabo con base en las premisas teóricas, del método etnográfico y de algunos del interpretativismo biográfico. De las narrativas recolectadas, se extrajeron las categorías y los temas culturales. De este modo, fue posible verificar que el proceso de la menopausia era entendido como resultado de una construcción singular, estando integrado a una red de significados, instituidos por el grupo, los cuales condicionan el conocimiento y la vivencia dentro de determinados patrones culturales, entre ellos, el hecho de que la menopausia significa dejar de ser mujer.

\section{DESCRIPTORES}

Menopausia.

Salud de la mujer.

Antropología cultural.

* Extraído da tese "Deixar de ser mulher: conhecimento e significado cultural da menopausa", Programa Interunidades Escola de Enfermagem e Escola de Enfermagem de Ribeirão Preto, Universidade de São Paulo, 2006. ${ }^{1}$ Professora da Universidade Estadual da Paraíba e do Centro Universitário João Pessoa. João Pessoa, PB, Brasil. gabymcc@bol.com.br ${ }^{2}$ Professora Titular da Escola de Enfermagem, Universidade de São Paulo (EEUSP). São Paulo, SP, Brasil. drgualda@usp.br 


\section{INTRODUCÃ̃}

A Organização Mundial da Saúde (OMS) considera ser a menopausa um evento biológico espontâneo e natural, que se refere ao último período menstrual do ciclo de desenvolvimento feminino, época da vida de uma mulher em que a capacidade reprodutiva cessa ${ }^{(1)}$. Entretanto, as mulheres enquanto sujeitos sócio-culturais têm modos de agir, de pensar, de sentir e de interpretar a menopausa com base na sua visão de mundo, decorrentes das relações e interações que estabelecem com as pessoas e o ambiente em que vivem. Assim sendo, não cabe apenas à biologia elucidar a vivência feminina nessa etapa da vida, mas às ciências humanas que reconhecem a menopausa como sendo mediada pelo contexto sociocultural e também pela história pessoal e familiar das mulheres.

Neste sentido, estudos etnográficos que enfocam o conhecimento e o significado da vivência da menopausa são importantes, uma vez que se constituem em abordagens necessárias de serem compreendidas, considerando o processo saúde-doença da mulher. Por essa razão, busca-se, neste artigo, relatar a pesquisa feita junto a um grupo de mulheres residentes na Paraíba, cujo objetivo foi compreender o conhecimento que se tinha sobre esse processo biológico e como ocorria a vivência feminina nessa etapa de vida.

Buscou-se respaldar este estudo nos fundamentos antropológicos, considerando que a cultura consiste em estruturas de significação socialmente estabelecidas, em função das quais as pessoas fazem certas coisas $^{(2)}$. Para o antropólogo, o homem é um animal amarrado a teias de significados que ele mesmo teceu, enquanto a cultura, conceito essencialmente semiótico, é constituída de teias de significados, cujas análises estão relacionadas às dimensões simbólicas da ação social e aos sistemas entrelaçados de signos e símbolos que permitem aos indivíduos e aos grupos a interpretação e a orientação de suas ações, proporcionando-lhes identidade social ${ }^{(2)}$.

Estudos vêm sendo desenvolvidos com o fim de demonstrar que a subjetividade feminina tem sido construída e modificada, tendo por base a sua inserção social nas

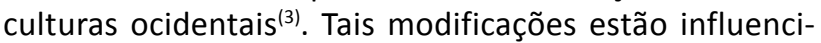
ando o modo de ser das mulheres, deslocando-as de meros papéis caracterizados pela passividade e resignação, ante o envelhecimento, para tornarem-se realizadoras de sonhos e desejos outrora postergados. E, conforme esse processo histórico tem avançado, de forma diferenciada em locais e espaços de tempo, verifica-se a constatação de que as mulheres estão atuando fortemente na transformação da sociedade, particularmente no que tange à vivência da menopausa ${ }^{(4)}$.

\section{REFERENCIAL METODOLÓGICO}

Considerando que o interesse da pesquisa estava voltado pra a compreensão do que as mulheres, em seus contextos culturais naturais, pensavam, sentiam e sabiam sobre a menopausa, procurou-se buscar subsídios nos referenciais teóricos da antropologia interpretativo-médica e no método etnográfico. Inicialmente, examinou-se a contribuição específica da abordagem antropológica e, por conseguinte, da influência do contexto cultural sobre as maneiras de pensar e as formas de agir das pessoas diante dos eventos da vida.

A antropologia interpretativa, enquanto projeto de análise cultural, propõe-se a compreender a partir da interpretação do discurso. Destarte, o indivíduo, que outrora era retratado como sujeito à cultura da qual fazia parte e um mero repetidor de comportamentos previamente aprendidos, passa a ser considerado sujeito da própria cultura, o que implica em um reconhecimento da cultura enquanto processo ${ }^{(5)}$.

A antropologia médica estuda como as pessoas explicam as causas, os tratamentos das doenças e como as enfrentam, considerando as diferenças entre as culturas e os grupos sociais ${ }^{(6)}$. Este ramo da antropologia também estuda como essas crenças e práticas estão relacionadas com mudanças biológicas e psicológicas no organismo humano, tanto na saúde como na doença. É nesse sentido que se buscou resgatar a antropologia médica, numa tentativa de compreender qual o significado da menopausa para mulheres, entendendo esse fenômeno como uma mudança biológica e psicológica, sobre a qual fatores sociais e culturais, que interagem no curso da história de vida, exercem fortes pressões.

No que se refere à opção pelo método etnográfico, deve-se ao fato de o mesmo procurar uma explicação descritiva da vida e da cultura em um dado sistema social, com base em observação detalhada daquilo que as pessoas de fato fazem ${ }^{(7)}$. A abordagem etnográfica é construída tomando-se como base a idéia de que os comportamentos humanos só podem ser devidamente compreendidos e explicados na sua referência com o contexto social ${ }^{(8)}$.

Nesta perspectiva, estudos buscam revelar a complexidade da experiência no processo saúde-doença e, para tanto, lançam mão da etnografia para descrevê-lo, pois o mesmo adquire relevância na voz, em forma de narrativa, daqueles que compartilham a experiência de vivenciar, explicar e interpretar os eventos. Assim, consideram a narrativa como um evento social e não como texto fixo. Esta técnica é utilizada como elemento conceitual e metodológico que intervém de maneira fundamental na construção do conhecimento antropológico em saúde. 
Por essa razão, os estudiosos da área reconhecem que, sob esta ótica, o foco de análise passa a ser sobre os significados que emergem da interação social, levandose em consideração a realidade concreta dos indivíduos. O trabalho do etnógrafo seria, então, desvendar os significados imbricados nas relações sociais. Geertz, expoente da antropologia interpretativa e responsável pela inclusão do paradigma hermenêutico nesta área, conceitua cultura como sistemas entrelaçados de signos interpretáveis, não sendo, portanto, um poder ou algo ao qual podem ser atribuídos casualmente os acontecimentos sociais, os comportamentos, as instituições ou os processos; ela é um contexto, algo dentro do qual esses sistemas podem ser descritos com densidade ${ }^{(2)}$.

\section{MÉTODO}

Este estudo etnográfico foi desenvolvido com mulheres residentes na Comunidade Salinas do Ribamar, que fica localizada acerca de $15 \mathrm{~km}$, ao sul de Cabedelo, município do litoral paraibano, na área geográfica da grande João Pessoa.

Para composição da amostra, optou-se pelos seguintes critérios de inclusão de informantes ${ }^{(9)}$ : ter tido menopausa espontânea (ausência de menstruação excluindose gravidez / amamentação / procedimentos cirúrgicos ou terapêuticos); não fazer uso de terapia de reposição hormonal; concordar em participar livre e conscientemente do estudo; residir na comunidade há pelo menos um ano; ter tempo disponível para participar da pesquisa; desejar partilhar a experiência de vivenciar o processo da parada das menstruações e ter condições físicas, cognitivas e emocionais que possibilitassem estabelecer um nível de comunicação necessária à coleta de dados e desenvolvimento da pesquisa. As informantes compuseram um conjunto diversificado, sendo detentoras dos atributos que se pretendia investigar.

Durante a pesquisa, adotou-se os princípios éticos dispostos na Resolução $n^{\circ}$ 196/96 do Conselho Nacional de Saúde $(\mathrm{CNS})^{(10)}$, deixando as colaboradoras cientes do respectivo objetivo e ainda esclarecidas e livres para a participação, podendo interrompê-la no momento que lhes conviesse e com a certeza de que os resultados retornariam para discussão na comunidade.

O projeto de pesquisa, em pauta, foi aprovado pelo Comitê de Ética em Pesquisa com Seres Humanos da Escola de Enfermagem da USP (Processo n. 477/2005) e para realização do estudo, foi também obtida a autorização da Direção de Atenção à Saúde da Secretaria Municipal do Município de Cabedelo.

Ao se pretender compreender os significados, lançouse mão, para coleta de dados, da observação participante e da entrevista em profundidade. Aquela, além de possibilitar um impregnar-se, um contaminar-se pelos valores do grupo, constituiu-se em ferramenta essencial do processo, uma vez que possibilitou compreender os fenômenos e direcionou para reflexões e conclusões ${ }^{(11)}$. Já a entrevista objetivou buscar os sentidos atribuídos pelas mulheres aos fatos e às coisas do mundo, numa tentativa de acessar a sua perspectiva e perceber o que dificilmente seria observado diretamente, tais como: sentimentos, pensamentos e intenções ${ }^{(12)}$.

O primeiro encontro foi marcado por interação e troca, sob uma atmosfera favorável que pressupunha influência recíproca entre os envolvidos. Cada momento de fala, escuta e descobertas foi ímpar porque únicas são as mulheres nos seus contextos culturais ${ }^{(13)}$. Há de se considerar também que, para as informantes, constituía-se em oportunidades de revelar sua posição frente ao objeto questionado e, assim, fazer surgir os conflitos que vivem ou viveram, além de possibilitar meios de mostrar como o seu mundo funciona. Para tanto, utilizou-se um roteiro de entrevista semi-estruturado, com questões norteadoras.

Fez-se a opção por se realizar uma segunda sessão para complementar as entrevistas. Nesse segundo encontro, solicitou-se que as doze colaboradoras acrescentassem em uma silhueta feminina, previamente reproduzida, como visualizavam internamente o corpo ou, para aquelas que não entendiam a formulação da proposta, que desenhassem aquilo que está envolvido com menstruação, gravidez e menopausa. Objetivou-se, nesse momento, motivar as colaboradoras a falarem a respeito da menopausa para se verificar o quanto a representação que elas têm do corpo influencia nos significados que possuem sobre a menopausa, e, ainda, favorecer uma interpretação compartilhada (pesquisadora-colaboradora) à medida em que, enquanto desenhavam, comentavam sobre os desenhos.

Convém ressaltar que a interpretação desenvolveu-se a cada momento do encontro em que as participantes descreviam situações vividas, e, a partir daí, novos significados eram atribuídos às suas experiências, sendo coconstruídos em um diálogo no qual o pesquisador, além de fazer perguntas, condensava e interpretava os significados descritos pelas participantes, até que houvesse uma interpretação possível ou ficasse evidente que um tema pode ser compreendido de diferentes formas ${ }^{(14)}$.

Para o tratamento dos dados localizaram-se, nas experiências relatadas, as frases ou afirmativas que se relacionavam diretamente ao fenômeno em questão, interpretando-as como um leitor informado, inspecionando os significados para verificar o que eles revelavam sobre os aspectos essenciais e recorrentes do fenômeno, proporcionando a compreensão por parte das participantes da pesquisa ${ }^{(15)}$. Dessas narrativas, culminaram, naturalmente, as categorias e os temas culturais.

Entende-se como categoria cultural a construção conceitual que tem como foco os elementos culturais definidos por uma expressão ou palavra(16). As categorias 
não foram prefixadas pelo roteiro das entrevistas, foram construídas após leituras sucessivas e intercaladas dos materiais e conseqüentes agrupamentos.

Neste estudo, os temas elencados surgiram das análises empreendidas e conduziram para a compreensão do significado cultural das mulheres no que se refere à menopausa. Eles são genéricos, abstratos e derivam das unidades de significado, comportamentos, observações e expressões verbais e não dos sujeitos, englobando categorias e convergindo para evidenciar os componentes das experiências ${ }^{(17)}$.

Para compreendê-los, foram utilizados, além do método etnográfico, pressupostos do método biográfico interpretativo ${ }^{(18)}$, conseguindo identificar nas narrativas: a existência do outro, os antecedentes familiares, os momentos marcantes, o gênero e a classe social, e as experiências marcantes ${ }^{(16)}$.

\section{AS CATEGORIAS CULTURAIS}

Os resultados obtidos na análise dos dados, em busca da compreensão do significado cultural da menopausa para um grupo de mulheres, demonstraram a singularidade do processo que tem a cultura como mediadora das experiências pessoais. $\mathrm{Na}$ análise dos dados, identificaram-se três categorias: corpo, menstruação e menopausa.

Entende-se que o CORPO é a estrutura física das pessoas e antes de ser um objeto de intervenção das ciências biomédicas, representa a extensão do próprio ser e permite a inclusão no mundo. Procurou-se, nesta categoria, apresentar os aspectos das narrativas das informantes relacionados ao conhecimento $e$ às fontes de informação sobre o corpo feminino, a vivência da sexualidade e o discurso sagrado. Esses aspectos constituíram-se em subcategorias, marcados pelas falas que seguem.

As mulheres, ao narrarem o significado da menopausa, referiram-se ao conhecimento e às fontes de informação sobre o corpo feminino. Os depoimentos caracterizam tal situação:

Ninguém tinha coragem de contar. Ninguém me explicou nada, não entendia nada de corpo da mulher...(Margarida).

... Às vezes fico pensando como é que DEUS faz um negócio só para sair coisa boa e coisa ruim, porque sai mijo, boi, menino, quem já viu...(Violeta).

A imagem da estrutura e funcionamento interno que se tem do corpo influencia, sobremaneira, a percepção dos eventos e a experiência corporal. Pôde-se constatar que as informantes, em relação ao conhecimento do corpo, têm uma dimensão individual, que se reporta ao sentido existencial da experiência corporal muito comprometida, estando evidente que as dimensões social e política são as que imperam entre elas.
Considerou-se que a vivência da sexualidade não termina com o envelhecimento. Na menopausa ocorrem modificações no corpo e na resposta sexual, mas o interesse pelo sexo existe uma vez que a idade não dessexualiza a velhice. $O$ que parece influenciar sobremaneira a vivência da sexualidade e a vida sexual são os aspectos psicológicos e culturais e as crenças religiosas. As mulheres interpretam como sendo a vontade de Deus, que se manifesta como um sinal no corpo para que o ato sexual seja abandonado, uma vez que a procriação já não é mais possível. Nesse sentido, parece se instalar uma fase de recolhimento erótico, como explica o discurso que segue:

... Depois de certa idade, a gente tem é que somente ajudar o marido, cuidar da casa, dos filhos, ajudá-los, e rezar pra Deus. É isso que os velhos devem fazer. Essas outras coisas ficam pros jovem. Para que fazer estas coisas se nem filho podem vir mais?... (Margarida).

O discurso sagrado e a fé declarada pelas mulheres foram descritos como elementos de ajuda na compreensão e aceitação da vivência da menopausa, que pode ser reconhecido nas falas abaixo:

... Deus manda para o corpo o sinal de ser mulher e de deixar de ser mulher... (Violeta).

... DEUS sabe de tudo, manda virar moça para casar, cuidar de casa e ter filho e, com os tempo tira isso que para a mulher viver a velhice assossegada (Lírio).

Para a antropologia, a religião é parte de todas as culturas sendo um importante quadro de referência pessoal, que carreia crenças e valores, apontando o significado não só para as situações imediatas vivenciadas, mas também para as razões do homem no mundo.

A categoria MENSTRUAÇÃO se subdividiu nas subcategorias: os significados do sangue menstrual, a relação com a menstruação, a relação entre menstruação e reprodução, os conhecimentos e as fontes de informação, conforme serão apresentadas a seguir.

Considerando que toda a vida da mulher é demarcada pelos ciclos de sangue, nascimento, menstruação (menarca), defloramento, gravidez, parto e menopausa, buscou-se compreender os significados do sangue menstrual. Percebeu-se que as mulheres não sabem dizer qual é o conteúdo da menstruação, pois muitas acreditam que ela seja um processo de limpeza do corpo, sendo o fluxo mensal constituído de impurezas, desconhecendo o mecanismo menstrual e revelando uma explicação marcada pela influência religiosa. Isso evidencia de maneira inequívoca que a falta de educação sexual faz perpetuar muitos mitos:

Pensava somente que a menstruação era o sangue sujo que a gente botava para fora (Íris).

Nesse contexto, verificou-se que as mulheres descrevem o sangue menstrual com dois significados: um negativo, construído em torno da idéia de sujeira; e outro positivo, construído em torno da definição de ser mulher. 
As mulheres da comunidade tinham uma difícil relação com a menstruação, uma vez que para muitas o uso dos panos associa-se à sujeira, a uma região do corpo cercada de tabus e de vergonha, e, ainda, impondo inúmeras limitações:

Quando tava menstruava era como tava de resguardo: não levava sol, chuva nem sereno, não passava debaixo de cerca nem de arame e tinha que andar os dias com um pano amarrado na cabeça para não levar pancada de vento. E tinha um monte de coisa que não podia comer, coisa carregada, era uma novela. Por isso também que às vezes penso que não menstruar é bom (Violeta).

Observa-se nos relatos uma relação entre a menstruação e a reprodução. Aquela foi reconhecidamente o fenômeno fisiológico ligado à reprodução desde a puberdade até a menopausa. Dessa forma, a menarca é um indicativo de que a menina / mulher é fértil, sendo, portanto, capaz de engravidar.

Depois entendi que quando não menstruava era sinal de menino Tive seis filhos, não dava nem tempo entre um e outro nem despareava (Jasmim).

Em relação aos conhecimentos e fontes de informação sobre a menstruação, as informantes referiram que este não era assunto discutido entre mães e filhas antes de seu acontecimento. Aprendia-se pouco sobre os processos do corpo, pois não se falava ou discutia sobre o assunto. As mulheres aprenderam, apenas observando o comportamento das outras, que, com a menarca, tinham alcançado a idade adulta e podiam ser mães.

Na categoria MENOPAUSA, a fala das mulheres descreve os significados apreendidos nas entrevistas, baseados em suas experiências. Esta categoria abrange as subcategorias que seguem: as mudanças percebidas; as explicações para a parada da menstruação; os estigmas; a experiência de viver a menopausa; a vivência das outras mulheres da comunidade; os conhecimentos e as fontes de informação e, por fim, a denominação do período.

Pelas narrativas analisadas, considerando esse cotidiano social e cultural, verificou-se que as mudanças percebidas não são hoje encaradas como grandes dificuldades a serem enfrentadas ou como doença que requer tratamento médico. Para as mulheres, a constatação das mudanças no fluxo menstrual, as ondas de calor e a secura vaginal foram consideradas, a princípio, como preocupantes, pois não tinham informações claras sobre a normalidade desses achados. Ora interpretavam essas mudanças como sendo sinais do corpo e ora procuravam os profissionais de saúde (quase sempre médicos) para que fosse comunicada a chegada da menopausa. Algo tão particular, tão individual, passa a ser reconhecido por outrem. Veja-se:

Passou-se três meses sem vir. Eu até pensava que era gravidez ... melou mais duas vezes só e depois nunca mais veio, falhou de vez. Foi Assim desse modelo no meu corpo. Somente soube que estava na menopausa porque falhou e por causa de que a médica disse (Lírio).

Considerando o conhecimento sobre o corpo feminino, iniciou-se a buscar pelas explicações para a parada da menstruação. Muitas mulheres se sentiram incapazes de explicar porque a menstruação cessa como foi expresso por Orquídea:

... sei não, sei não, nunca pensei nisso não. As mulher do meu tempo não são de ficar procurando o porquê disso, daquilo outro... pra que vou ficar pensando em coisa que não sei nem dou jeito mesmo.

A explicação da menopausa, como algo que veio de Deus, remete a algo bastante comum nesta comunidade, que consiste em conferir dimensão sobrenatural àquilo que não conseguem explicar e/ou entender.

Esse é o tempo da mulher não menstruar mais. Deus sabe de tudo, manda virar moça para casar, cuidar de casa e ter filho e com o tempo, tira isso que para a mulher viver na tranqüilidade a velhice. Então é isso que acho que faz a menstruação parar: o gosto de DEUS (Lírio).

O contexto cultural no qual as mulheres estão imersas influencia as experiências de viver a menopausa. Neste estudo, constatou-se que as mulheres, em sua maioria, expressaram uma experiência positiva. Todavia, algumas consideraram a menopausa uma experiência negativa e outras se mostraram indiferentes ou circularam entre os grupos.

Achei bom a parada da menstruação... tinha muita vergonha de lavar aqueles pano..Depois inventaram o modess mas tinha mês que era difícil de comprar por causa das condições da gente. Por isso que achei bom (Açucena).

Para mim foi difícil. Foi nada, tá sendo não pelo calor e pela regra que não desce mais. Mais porque ainda não tive corage de dizer pro meu marido que não sou mais mulher (Lírio).

... para mim foi bom e ruim. Do lado ruim foi por causa desse calor e desse suor frio... E achei foi bom porque como já disse não me preocupava mais com nada mesmo. Como tinha dois homem podia fazer qualquer coisa, qualquer dia despreocupada (Violeta).

Mesmo aquela que descreveu a experiência de forma difícil de ser enfrentada não a fez abordando a menopausa como condição patológica difícil de suportar e /ou conviver diante das modificações no corpo. Parece que a dificuldade acaba sendo muito pela valorização do que os outros atribuem ao fato do que pela constatação do envelhecimento.

Nesse sentido, os comentários sobre a vivência da menopausa das mulheres da comunidade retratam de forma geral uma ambivalência que considera aspectos positivos e negativos. Os depoimentos abaixo refletem essa situação 
... já ouvi uma mulher dizendo que foi feito eu: tranqüilo, tranqüilo. Mas já teve umas que disse que não. Aí eu fico naquela: será que é assim mesmo ou é inxagero desse povo. Mas já vi essas duas conversa. E essas que dizem que adoece diz que fica com o corpo seco, problema de osteoporose, por causa que os ossos se desmanchando, diz um monte de coisa (Lírio).

Dessa forma, contatou-se que a interpretação da menopausa e as reações oriundas a partir desse processo biológico são influenciadas por estigmas. $O$ conceito de estigma envolve o processo formativo geral e as formas de ver-se e ser visto pelo social mais amplo, por um outro indivíduo ou grupo particular, como um indivíduo marcado e que deve ser submetido a um olhar diferenciado e piedoso(19). Segundo esse estudioso, referências à mulher na menopausa são feitas utilizando-se rótulos negativos como velha, aquela que virou homem, calorenta e seca, o que vem desqualificá-las, passando a serem reconhecidas pelos aspectos negativos associados à menopausa.

Para estas mulheres, a menopausa é uma palavra usada popularmente para denominar o período e descrever os anos em que os ciclos menstruais estão modificando o corpo da mulher, além do que fazem referência ao último evento menstrual e indicam, pela categoria verbal, uma redefinição da mulher no sentido de sua atuação social, como se constatou no depoimento seguinte:

Por aqui a gente diz que não é mais mulher, que a mulher ficou seca, que a mulher virou homem e agora não se limpa mais (Açucena).

Fato curioso é que existe na linguagem regional outra denominação que pode ser percebida no depoimento abaixo

\footnotetext{
Diz que a mulê secou por dentro, que deixou de ser mulê. $E$, né isso não que os povo rico chama de menospausa. Porque os nome muda de pobre para rico. Olhe bem:a médica do posto chama gonorréia e isso a gente chama pingadeira, ela diz que a mulher ta grávida a gente diz buxuda mesmo, Quando um homem rico trai a mulher dizem que ele deixou de gostar, já por aqui diz que ela levou cangalha mesmo. Sei que o nome é menopausa mais por aqui a gente diz que deixou de ser mulher (Lírio).
}

Para compreender a experiência da mulher, buscou-se apreender os conhecimentos e as fontes de informação, ou seja, o que ela sabe sobre a menopausa e onde obteve esta informação. Assim sendo, detectou-se que as mulheres sabem a idade na qual podem esperar que aconteça a menopausa e reconhecem as primeiras modificações percebidas no corpo, o que as causa e porque ocorre a parada da menstruação. Mas no cotidiano, elas não tinham pensado na menopausa e se tratavam sobre o assunto, centravam-se apenas na descrição de sintomas, como por exemplo, as ondas de calor.

\section{OS TEMAS CULTURAIS}

Organizadas as categorias que emergiram do discurso das mulheres, referentes à compreensão e vivência da menopausa, realizou-se um exercício de integrar os achados expressos nas narrativas, considerando o contexto das experiências para, somente então, interpretá-los tendo como pano de fundo o cenário sócio-cultural local, atribuindo-Ihes significados e dando origem aos seguintes temas culturais: a menstruação caracteriza a mulher $e$ define seu papel; o corpo emite os sinais; o poder de Deus determina as funções do corpo; a menopausa como evento natural do corpo e a menopausa e o deixar de ser mulher. Considerando o surgimento dos temas citados, verificouse que possuem valores significativos enquanto elementos estruturais da vida das mulheres.

\section{A menstruação caracteriza a mulher e define seu papel}

A vida das colaboradoras é demarcada pelos ciclos de sangue: menstruação, gravidez e menopausa. Para essas mulheres, a menstruação extrapola seu caráter biológico, contemplando um significado social. Mediante apresentação da fala de Açucena, ratifica-se este significado: ... a gente precisa virar mulher para casar e ter menino $e$ depois voltar a ficar menina para se apartar dessas coisa.

Para as mulheres deste estudo, a menstruação, o casamento, a sexualidade e a procriação estão intrinsecamente relacionadas e determinam o papel feminino que têm a desempenhar, social e culturalmente, como mulheres, mães e donas-de-casa. Para elas, a presença das menstruações não só sinaliza as possibilidades de procriação, mas interfere na vivência sexual, de forma que sua ausência gera transformações importantes em seus vínculos conjugais.

Assim, de acordo com o que foi exposto pelas entrevistadas, a menstruação tem caráter positivo, indicando fertilidade e mudanças no corpo, desde a menarca, ao contrário da menopausa que traz cargas negativas, gerando não somente a infertilidade mas também a ausência do desejo sexual. Todavia não se pode acreditar que a identidade feminina esteja assentada exclusivamente no papel que desempenha para reprodução humana.

\section{O corpo emite os sinais}

As representações que elas fizeram sobre o corpo revelam que conhecem a existência de alguns eventos biológicos, entretanto, não sentem ou sentiram necessidades de elaborar explicações para que esses ocorram conforme explicitados por Jasmim: Tem coisa que não precisa saber porque o corpo dá o caminho e vai dando o sinal de tudo. Talvez estas mulheres tenham grande habilidade para escutar o corpo, pois ele conta suas histórias e em cada uma delas há um sentido, nada sendo esquecido, mas revelado no momento oportuno. 
A sociedade tem sido cruel com o corpo em idade avançada, vivenciando a menopausa, visto que tais fatos são percebidos como símbolos sociais do envelhecimento. $\mathrm{O}$ corpo envelhecido é excluído com pouca ou nenhuma consideração e, algumas vezes, até com desafeto. A sociedade instituiu uma concepção e um modelo social de corpo que estão voltados para a juventude.

Embora o conhecimento e a vivência de cada mulher sejam individuais, existem traços comuns nas experiências relatadas. Para as entrevistadas, o corpo emite, na menopausa, os sinais de mudança, percebidos através dos ciclos menstruais, do calor e da secura nas partes.

As mudanças corporais percebidas conduziram as mulheres a elaborarem uma re-significação de seus corpos e o sentido de suas vidas. Esta re-significação só foi possível graças à aceitação da alteração da imagem e da função corporal, significando uma conformação frente ao evento que não se pode resistir.

Cada uma das mulheres reconheceu a menopausa como um evento natural e normal na vida, fenômeno característico de corpos com idade avançada. As mudanças percebidas não foram interpretadas como doença. Dessa forma, as mulheres consideraram-se geralmente felizes por seus corpos terem cumprido o destino esperado.

\section{O poder de Deus determina as funções do corpo}

$\mathrm{Na}$ tentativa empreendida para explicar a parada da menstruação, as colaboradoras recorreram ao poder divino de forma bastante resignada. As respostas oferecidas pelas mulheres reafirmaram a idéia de destino natural do corpo feminino, segundo a vontade de Deus. Elas se ampararam nesse pensamento para preservar sua autoestima, acreditando que cumpriram a vontade divina. Para elas, a exemplo de Violeta, Deus foi quem fez a mulher... Pois bem, ele fez esse lugar para menino ficar, para fazer a faxina e para jogar fora o xixi

Reconhecendo que Deus disse que tudo tem tempo para acontecer, Margarida atribui, também, a Ele, a determinação da menarca e da menopausa. Ficou evidente que existe uma convenção extra-oficial religiosa impondo que, depois que a mulher deixa de menstruar, o sexo deve acabar.

A religiosidade tem marcante presença no cotidiano dessas mulheres e transparece nas mais insignificantes atividades e explicações. Deus está em todo lugar e a toda hora sua invocação é comum. A sensação que fica é a de que Deus é uma presença familiar com grande interferência para explicar todas as situações cotidianas vivenciadas.

Percebeu-se que a religiosidade destas mulheres levam-nas a aceitar as situações cotidianas incompreensíveis de forma mais amena, pois Deus assume a dimensão de orientação ao viver, sem que seja necessário perguntar o porquê, como expresso por Peônia: Porque tem tanta coisa que ele manda que nóis não entende e é só para aceitar e pronto.

\section{A menopausa como evento natural do corpo}

Os discursos demonstraram que estas mulheres comportam-se de maneira semelhante respeitando suas particularidades, o que confere à cada fala uma especificidade na interpretação da sua realidade. Para elas, ... toda muIher nasce, cresce, menstrua, casa, tem filho e fica velha, conforme expressou Hortência.

Verificou-se, para elas, a vida é um passar contínuo de situações determinadas pela Biologia: nascimento, infância, puberdade (menarca), maturidade (gravidez), velhice (menopausa) e morte. Esse é o destino natural das mulheres e a passagem de uma situação para outra é eventualmente ganho e perda de status. Essa compreensão foi o fio condutor das narrativas, traduzindo a linguagem da memória e a força viva da cultura.

A menopausa não é uma experiência estática, estando relacionada às condições biológicas, psicossociais e espirituais, além das influências culturais de cada sociedade. Sugere julgamentos, tanto positivos quanto negativos, de cunho biológico, moral, psicológico e cultural, tanto da mulher quanto dos que convivem com ela.

As imagens negativas do envelhecimento, que acompanham a construção do significado da menopausa, sustentam o preconceito e encontram-se explícitas nas falas das mulheres, conforme se pode exemplificar quando Jasmim diz: ainda eram muito novas para começar a ficar velha...

Em contrapartida, a menopausa para algumas mulheres significou ser sinônimo de liberdade dos martírios mensais que as menstruações provocavam.

Detectou-se certo estranhamento em algumas mulheres que vivenciarem a menopausa sem os problemas de que tanto escutaram falar, como se ver na afirmação de Lírio: mudou muito não, até por aqui não... mas, diz o povo que a menopausa é a pior doença para a mulher. Tô esperando só queria que ele não chegasse não.

\section{A menopausa e o deixar de ser mulher}

Considerando ser a menopausa um processo universal que atinge todas as mulheres, parece que foi a perda da capacidade de procriação e, conseqüentemente, de sua identidade de mulher e do status social, a repercussão mais referida neste meio social. Foram marcantes as falas sobre a certeza de término da vida, enquanto mulher, em razão da menopausa, como podemos constatar na fala de Lírio: Aqui diz que, quando a mulher deixa de menstruar, vira homem... .

Para as mulheres, é o sangue menstrual que as definiam como tal à medida que as aproximam ou distanciam 
dos domínios masculinos. A identidade feminina e os papéis sociais, possivelmente, devem ter sido construídos pela própria mulher e pelo discurso médico considerando o processo biológico da menstruação nos mais diferentes momentos de sua vida.

A realização da mulher, outrora, esteve ligada à maternidade. Com o avançar da idade, esse significado foi também transferido para a ocupação com a casa / marido / filhos e netos, como demonstrado no relato de Rosa: com os tempos vai deixando de ser mulher... e fica como mãe, dona de casa e assim vai... .

Enquanto a menstruação significou o ser mulher e representou um marcador importante da transição à maternidade, a menopausa significou o deixar de ser mulher. Acredita-se que foram as atitudes e experiências das participantes sobre menstruação e maternidade que deram forma à base de suas interpretações do evento. Causou surpresa o fato delas, reiteradas vezes, definirem este período da vida como sendo aquele em que deixam de ser mulher.

Imersa nos aspectos da natureza e da cultura, a muIher encontra palavras para uma nova definição de si mesma, não em função da capacidade de reprodução, mas, agora, em função de seus novos papéis sociais. Quando esses papéis são necessários para a família favorecem um soerguimento da auto-estima.

Ao analisar os temas, é possível inferir que as mulheres em suas narrativas autobiográficas, resgatam e classificam seus conhecimentos e suas experiências e ratificam os significados atribuídos à menopausa, como diz Violeta: porque para o povo deixei de ser mulher.

\section{REFERÊNCIAS}

1. World Health Organization (WHO). Research on the menopause in the 1990s: report of a WHO Scientific Group. Report. Geneva; 1996. (WHO-Tecnical Report Series, 866).

2. Geertz C. A interpretação das culturas. Rio de Janeiro: Guanabara Koogan; 1989.

3. Sanchez M, Roel I. El processo de envejecimiento en la mujer. Tiempo Portal Psicogerontología [periódico na Internet]. 2001[citado 2003 fev. 21];(8). Disponível em: http://www.psiconet.com/tiempo/8

4. Del Priore M. História das mulheres no Brasil. São Paulo: Contexto; 2000.

5. Eckert C. A antropologia na atualidade. Revista Anos 90. 1994;10(2):7-35.

6. Helman CG. Cultura, saúde e doença. Porto Alegre: Artes Médicas; 1994.

\section{REFLEXÕES}

O estudo revelou que as mulheres interpretam a menopausa, a partir dos conhecimentos, das crenças e dos padrões culturais que adquiriram, ao longo da vida, nas relações sociais, arraigados ao contexto cultural da localidade. Pode-se, então, considerar que os temas sintetizam o significado da menopausa para as mulheres dessa localidade.

O contexto social, o modelo de atendimento médico, a concepção das mulheres sobre o corpo e a menstruação influenciaram, sobremaneira, seus conhecimentos e vivências a respeito da menopausa.

Acredita-se que a aproximação entre os campos técnico-científico e cultural, difundida pela perspectiva antropológica a respeito da menopausa, propiciará mudanças na postura dos profissionais envolvidos na assistência à saúde da mulher em todo o ciclo de sua vida. O desafio parece estar em reunir esforços que viabilizem essa mudança, favorecendo assistência integral e humanizada.

A menopausa é reconhecida como um acontecimento individual e, por essa razão, generalizações não foram por nós pretendidas. Compreender e interpretar a vivência da menopausa, neste grupo de mulheres, foi a contribuição teórica que se procurou apresentar nesta pesquisa. Realizou-se um esforço no sentido de contribuir para pensar a saúde da mulher de forma mais justa, individualizada e humana.

Compreendeu-se que o conhecimento sobre a menopausa, para este grupo de mulheres, constituiu-se em um processo singular, construído ao longo de suas vidas, representado por metáforas, que refletem a realidade cultural e social da localidade, para a qual a vivência da menopausa significa DEIXAR DE SER MULHER.
7. Jonhson AG. Dicionário de sociologia: guia prático da linguagem sociológica. Rio de Janeiro: Jorge Zahar; 1997.

8. Victoria CG, Kanuth DR, Hassen MNA. Pesquisa qualitativa em saúde: uma introdução ao tema. Porto Alegre: Tomo Editorial; 2000.

9. Turato E. Tratado de metodologia da pesquisa clínicoqualitativa: construção teórica-epistemológica, discussão comparada e aplicação nas áreas de saúde e humanas. Petrópolis: Vozes; 2003.

10. Conselho Nacional de Saúde. Resolução n. 196, de 10 de outubro de 1996. Dispõe sobre diretrizes e norma regulamentadoras de pesquisas envolvendo seres humanos. Bioética. 1996;4(2 Supl):15-25.

11. Martins JC. O método etnográfico: uma ferramenta viável na investigação da cultura de organizações. In: Anais da Conferência Internacional do Brasil de Pesquisa Qualitativa/Núcleo de Pesquisa da Família - NPF; 2004 mar.; Taubaté, SP, Brasil. p. 368. 
12. Patton MQ. Qualitative research and evaluation methods. Thousands Oak: Sage; 2002.

13. Santana CS. Girando o caleidoscópio: a formação de novas imagens no trabalho de olhar para os dados da pesquisa qualitativa. In: Conferência Internacional do Brasil de Pesquisa Qualitativa/Núcleo de Pesquisa da Família - NPF; 2004 mar.; Taubaté, SP, Brasil. p. 368.

14. Macedo RMS, Kublikowski I, Grandesso MA. A interpretação em pesquisa qualitativa: a construção do significado. In: Conferência Internacional do Brasil de Pesquisa Qualitativa/ Núcleo de Pesquisa da Família NPF; 2004 mar.; Taubaté, SP, Brasil. p. 83.

15. Janesick VJ. The choreography of qualitative research design. In: Denzin NK, Lincoln YS. Handbook of qualitative research. Thousand Oaks: Sage; 2003. p. 379-99.
16. Denzin NK. Interpretative biography. London: Sage; 1989.

17. Desantis L, Ugarriza DN. The concept of theme as used in qualitative nursing research. West J Nurs Res. 2000; 22(3):351-72.

18. Melleiro MM, Gualda DMR. O método biográfico interpretativo na compreensão de experiências e expressões de gestantes usuárias de um serviço de saúde. Rev Esc Enferm USP. 2003;37(4):69-76.

19. Goffman E. Estigma: notas sobre a manipulação da identidade deteriorada. 4a ed. Rio de Janeiro: LTC; 1988. 